\title{
PERBANDINGAN TEKS CERITA AJI SAKA DALAM TRADISI TULIS MASYARAKAT SUNDA
}

\author{
Mamat Ruhimat \\ Taufik Ampera \\ Rahmat Sopian
}

Fakultas Ilmu Budaya Universitas Padjadjaran

\begin{abstract}
ABSTRAK
Tulisan ini merupakan hasil penelitian secara filologis dan resepsi terhadap teks-teks Cerita Aji Saka (CAS) yang terdapat di dalam khazanah pernaskahan Sunda lama. Penelitian terhadap CAS ditujukan untuk mendapatkan suntingan teks, hubungan antarteks, dan tanggapan masyarakat terhadap cerita tersebut. Metode yang dipakai dalam penelitian ini adalah metode kritik teks objektif dan metode interteks. Metode objektif digunakan untuk merunut silsilah naskah. Metode interteks digunakan untuk membandingkan versi-versi CAS sehingga dapat diketahui dari sumber mana versi-versi itu berasal. Naskah-naskah Sunda yang memuat CAS di dalam penelitian ini ada sebelas naskah. Hasil perbandingan antarteks menunjukkan bahwa Cerita Aji Saka sangat populer dalam tradisi tulis masyarakat Sunda. Di dalam naskah Sajarah Galuh, buku Gandasari, Sekar Aosan, dan roman Mantri Jero tokoh Aji Saka dilegitimasi sebagai tokoh sejarah yang benar-benar ada dan hidup pada abad ke-5 Masehi yang peranannya sangat mempengaruhi perkembangan kejiwaan pembacanya untuk meneladani budi pekerti dari peristiwa yang terjadi pada Cerita Aji Saka.
\end{abstract}

Kata Kunci: tradisi tulis, resepsi, teks

\begin{abstract}
This paper is the result of a research on philology study and reception of the texts of Cerita Aji Saka (CAS) in the treasures of Sundanense ancient manuscripts. The research of CAS aims to gain the text editing, intertextual connection, and the society's perception of the text. The research uses the methods of objective textual criticism and intertextuality. The objective method is used to trace the genealogy of the manuscript. The intertextual method is used to compare multiple versions of CAS to discover the source of every version. There are eleven Sundanese manuscripts containing CAS in the research. The result of intertextual comparison shows that Cerita Aji Saka is very popular in the literary tradition of Sundanese people. In the manuscripts of Sajarah Galuh, the books of Gandasari, Sekar Aosan, and the romance of Mantri Jero, the character of Aji Saka is legitimated as a historical figure that really existed and lived in the $5^{\text {th }}$ century $A D$ whose role has a great influence on the mental development of the readers to imitate the character and the events occurring in Cerita AJi Saka.
\end{abstract}

Keywords: literary tradition, reception, text

\section{PENDAHULUAN}

Naskah-naskah Sunda lama pada umumnya belum tergarap secara filologis. Sebagian besar masih tersimpan baik di museum-museum, perpustakaan dalam dan luar negeri, maupun koleksi lembaga dan perorangan yang tentu saja sangat menarik untuk diteliti. Penggarapan naskah yang serius sangat diperlukan untuk menjaga kelestarian dokumen kebudayaan dan menggali pesan-pesan yang terkandung di dalamnya untuk dimanfaatkan dalam kehidupan di masa sekarang dan yang akan datang. 
Pelestarian naskah lama tidak hanya terbatas sampai tingkat pengoleksian dan pengkatalogan. Pengkajian secara filologis yang disertai suntingan teks akan lebih bermanfaat bagi pelestarian dan pemanfaatan kembali teks-teks yang sudah dilupakan oleh masyarakat pemiliknya.

CAS merupakan salah satu khazanah Sastra Sunda yang berkembang terus sampai sekarang. Cerita ini tidak saja tersurat di dalam naskah-naskah lama tetapi juga masih menjadi bahan bacaan dalam buku pelajaran di sekolah (Insani, 1991). Hal ini membuktikan bahwa tanggapan dan penerimaan masyarakat Sunda terhadap CAS masih sangat besar. Sebagian besar orang Sunda masih percaya bahwa aksara Sunda (Cacarakan) dibuat oleh Aji Saka Raja Medang Kamulan.

Jika dilihat dari penyajian cerita, CAS ternyata memiliki variasi sesuai dengan persepsi dan penerimaan masyarakat. Tidaklah mengherankan kalau CAS terdiri dari versi-versi yang berlainan dan bermacam-macam. Hal ini akan sangat menarik untuk diteliti secara pragmatik untuk mengungkapkan sejauhmana masyarakat Sunda mengenal dan menerima CAS sebagai tokoh yang dimitoskan sebagai pencipta aksara Cacarakan.

Penelitian terhadap CAS difokuskan pada tekstologi, tanggapan dan penerimaan masyarakat Sunda terhadap CAS yang melahirkan berbagai macam versi dan bentuk cerita. Bagaimana mengungkapkan sejarah teks, tradisi dan transmisi teks, sehingga sumber teks bisa diketahui? Bagaimana tanggapan dan penerimaan masyarakat Sunda terhadap CAS dari dulu sampai sekarang?

\section{METODE PENELITIAN}

Metode yang dipakai dalam penelitian ini adalah metode penelitian deskriptif komparatif analisis. Metode deskriptif komparatif analisis digunakan untuk memaparkan atau memberikan gambaran tentang keadaan naskah yang diteliti berdasarkan hasil wawancara dengan penulis atau pemilik naskah, apa yang tercantum dalam katalog, dan informasi dari dalam naskah itu sendiri. Selanjutnya, hasil deskripsi tersebut dibandingkan dan diteliti untuk diketahui sebab-musababnya, duduk perkaranya, atau prosesnya (Badudu dalam Ma'mun, 1998a: 50). Langkah selanjutnya adalah melakukan pengkajian terhadap naskah.

Teknik penelitian yang dilakukan untuk mencari naskah CAS bagi sumber data penelitian ini melalui studi pustaka dan studi lapangan. Studi pustaka dilakukan untuk mencari informasi naskah-naskah Sunda lama yang memuat CAS baik dalam katalog maupun hasil penelitian. Berdasarkan informasi dari hasil studi pustaka selanjutnya dilakukan studi lapangan untuk mencari keberadaan naskahnaskah CAS tersebut. Dari sebelas (11) naskah CAS yang diinventarisasi, baru dua (2) naskah yang ditemukan. Kedua naskah tersebut tersimpan pada koleksi Perpustakaan Jurusan Sastra Daerah Fakultas Sastra Universitas Padjadjaran di Bandung. Buku bacaan yang memuat CAS ada empat (4) judul yaitu: 1) Mantri Jero (Sastrahadiprawira, 1928, 1983), 2) Gandasari (Sastraatmadja, 1951), 3) Sekar Aosan (Insani, Cetakan I 1991) dan 4) Sekar Aosan (Insani, Cetakan II 1991).

Metode kajian yang digunakan dalam penelitian ini adalah metode kritik teks objektif dan metode interteks. Metode objektif digunakan untuk merunut silsilah naskah. Metode objektif yang sampai kepada perunutan silsilah naskah disebut juga metode stema (Baried, 1994). Metode interteks digunakan untuk membandingkan versi-versi CAS sehingga dapat diketahui dari sumber mana versi-versi itu berasal. 


\section{HASIL DAN BAHASAN}

\section{Inventarisasi Naskah}

Berdasarkan hasil penelusuran dalam katalog, naskah-naskah Sunda lama yang memuat CAS berjumlah (11) buah, yaitu:

1) Sajarah Galuh (Plt.23) koleksi Perpustakaan Nasional RI,

2) Carios Wiwitan Raja-raja di Pulo Jawa (Plt.4) koleksi Perpustakaan Nasioanl RI,

3) KitabSajarah Sumedang (YPS32) koleksi Museum Pangeran Geusan Ulun Sumedang,

4) Kitab Waruga Jagat (NUB 1635/NIB 03) koleksi Museum Pangeran Geusan Ulun Sumedang,

5) Aji Saka (NBS.23) koleksi Universiteit Bibliotheek Leiden,

6) Cerita Bumi Sagaluh koleksi Universiteit Bibliotheek Leiden,

7) Wawacan Sajarah Galuh (Lor.7905) koleksi Universiteit Bibliotheek Leiden,

8) Medang Kamulan, koleksi Andi Kampung Cisondari Desa/Kec. Pasirjambu, Bandung (Ekadjati (Ed.), 1988).

9) Berdasarkan hasil temuan naskah dari masyarakat diperoleh dua buah naskah yang memuat CAS, yaitu:

10) Sajarah Galuh (SS 2162)

11) Babad Aji Saka (SSUP006A) koleksi Perpustakaan Jurusan Sastra Daerah Universitas Padjadjaran.

Selain itu CAS juga ditemukan dalam empat buku yang telah diterbitkan:

1) Mantri Jero (Sastrahadiprawira, cetakan pertama 1928, cetakan ke-3 1983)

2) Gandasari IV (Sastraatmadja, 1951)

3) Sekar Aosan (Insani, 1957)

4) Sekar Aosan (Insani, 1991).

Sampai saat ini, naskah yang telah ditemukan dalam kesempatan ini baru dua buah, yaitu Sajarah Galuh (SG) dan Babad Aji Saka, di samping keempat buku cetakan yang tercantum dalam daftar di atas.

\section{Perbandingan Teks}

Naskah yang dibandingan pada perbandingan teks baru satu buah yaitu Sajarah Galuh (SG) karena baru naskah ini yang berhasil dibuat transliterasinya. CAS dalam SG kemudian dibandingkan dengan Mantri Jero (MJ) dan Sekar Aosan (SA). Kedua buku ini dianggap mewakili CAS untuk perbandingan persepsi dan resepsi pengarang terhadap CAS.

MantriJero merupakan roman sejarah kehidupan bangsawan Sunda, khususnya kabupaten Nagara Tengah di Priangan Timur setelah ditaklukan oleh Mataram. Roman ini ditulis oleh R. Memed Sastrahadiprawira, diterbitkan pertama kali oleh Bale Poestaka pada tahun 1928 dan diterbitkan ulang oleh Rahmat Cijulang pada tahun 1983. CAS termasuk kedalam bagian cerita ketika Yogaswara sedang diajari menulis aksara Jawa (hana caraka) oleh ayahnya. Sedangkan Sekar Aosan merupakan buku bacaan anak Sekolah Dasar untuk menunjang mata pelajaran Bahasa Sunda. Buku yang disusun oleh Insani ini pertama kali diterbitkan tahun 1957 oleh Tarate dan diterbitkan ulang dengan revisi pada tahun 1991 oleh Pamugat. CAS termuat secara lengkap pada edisi tahun 1957 dan merupakan kutipan dari Gandasari IV (Sastraatmadja, 1951). Sedangkan pada edisi 1991 CAS bagian pertama dihilangkan dengan alasan undakusuk 'tingkat tutur' bahasa Sundanya kacau dan membingungkan siswa.

Berdasarkan ringkasan cerita, berikut ini perbandingan alur CAS yang ada pada SG, MJ dan SA. 


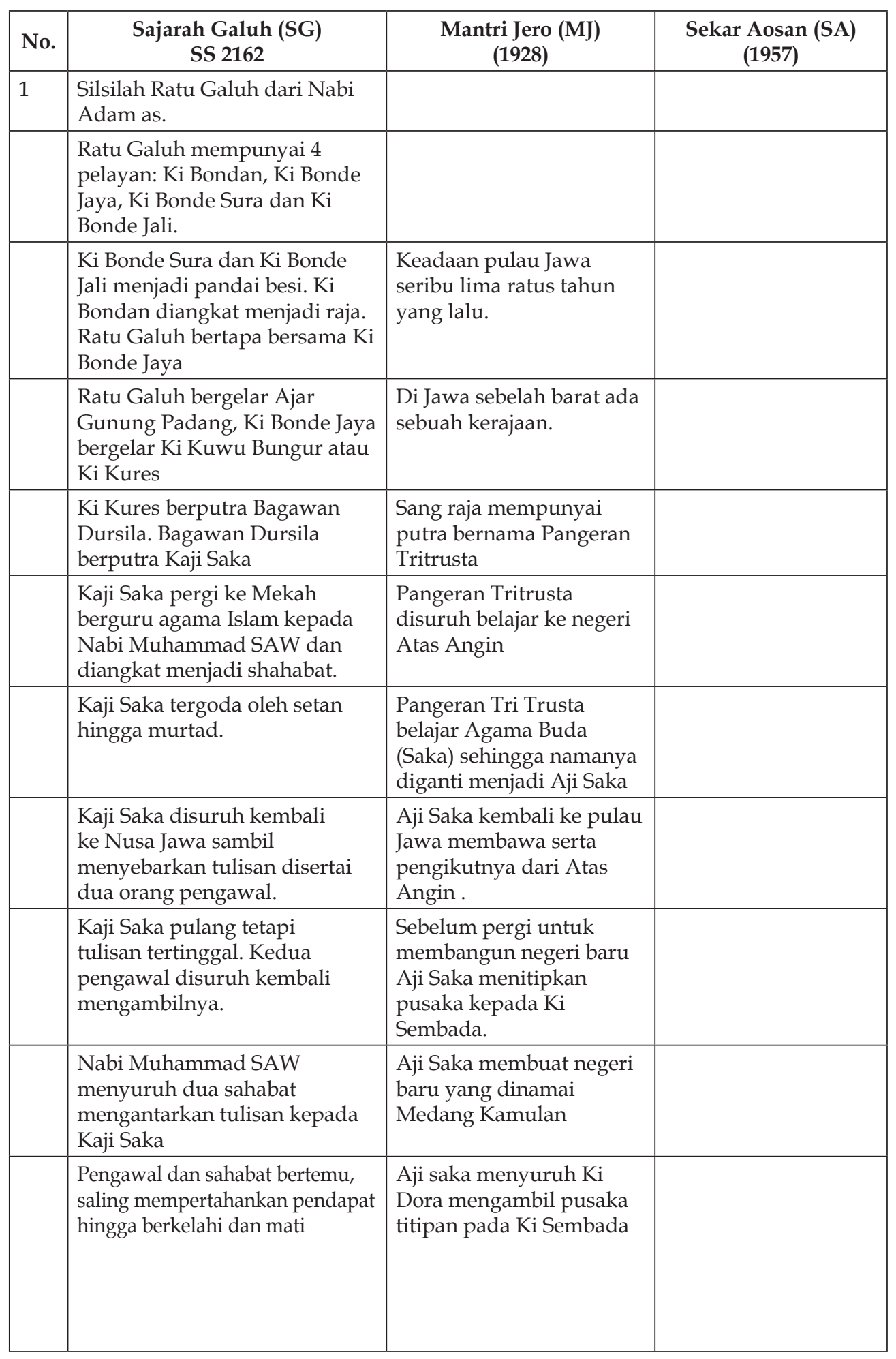




\begin{tabular}{|c|c|c|}
\hline $\begin{array}{l}\text { Kaji Saka mencari } \\
\text { pengawalnya dan ditemukan } \\
\text { telah mati bersama sahabat } \\
\text { Nabi. }\end{array}$ & $\begin{array}{l}\text { Ki Sembada tidak mau } \\
\text { memberikan pusaka itu } \\
\text { karena ingat akan wasiat } \\
\text { Aji Saka untuk tidak } \\
\text { memberikannya kepada } \\
\text { orang lain }\end{array}$ & \\
\hline $\begin{array}{l}\text { Kaji Saka membaca tulisan } \\
\text { yang berbunyi hana caraka } \\
\text { data sawala pada jayanya maga } \\
\text { batanga yang kemudian disebut } \\
\text { aksara Jawa. Hana caraka timur, } \\
\text { data sawala selatan, pada jayanya } \\
\text { barat, maga batanga utara. }\end{array}$ & $\begin{array}{l}\text { Kedua panakawan } \\
\text { berkelahi hingga terluka } \\
\text { parah. }\end{array}$ & \\
\hline $\begin{array}{l}\text { Kaji Saka pulang ke Nusa Jawa, } \\
\text { tinggal di rumah seorang janda } \\
\text { di Medang Kamulyan. }\end{array}$ & $\begin{array}{l}\text { Aji Saka menyusul ke } \\
\text { tempat Ki Sembada } \\
\text { dan melihat kedua } \\
\text { panakawannya luka } \\
\text { parah. }\end{array}$ & \\
\hline $\begin{array}{l}\text { Raja Medang Kamulyan, } \\
\text { Jawata Cengkar suka makan } \\
\text { manusia. }\end{array}$ & $\begin{array}{l}\text { Setelah kedua panakawan } \\
\text { menjelaskan ihwal } \\
\text { masing-masing mereka } \\
\text { pun mati }\end{array}$ & $\begin{array}{l}\text { Raja Medang } \\
\text { Kamulan bernama } \\
\text { Dewata Cengkar suka } \\
\text { memakan manusia }\end{array}$ \\
\hline $\begin{array}{l}\text { Kaji Saka mendirikan } \\
\text { sekolah di kampungnya dan } \\
\text { mengajarkan aksara Jawa }\end{array}$ & $\begin{array}{l}\text { Aji Saka membuat } \\
\text { peringatan atas kejadian } \\
\text { tersebut dengan } \\
\text { menuliskan aksara pada } \\
\text { sebatang kayu }\end{array}$ & \\
\hline $\begin{array}{l}\text { Ketika Kaji Saka sedang } \\
\text { buang air kecil ia melihat paha } \\
\text { janda tersingkap. Kamanya } \\
\text { keluar dan dimakan ayam } \\
\text { jantan hingga bertelur. Telur } \\
\text { disimpan di lumbung sebagai } \\
\text { jimat. }\end{array}$ & $\begin{array}{l}\text { Aksara tersebut berbunyi } \\
\text { hana caraka data sawala } \\
\text { pada jayanya maga batanga } \\
\text { atinya ada dua utusan } \\
\text { berkelahi sama kuatnya } \\
\text { hingga keduanya menjadi } \\
\text { mayat. }\end{array}$ & \\
\hline $\begin{array}{l}\text { Kaji Saka bertemu patih yang } \\
\text { sedang mencari manusia untuk } \\
\text { makanan Jawata Cengkar. }\end{array}$ & & $\begin{array}{l}\text { Patih bertemu seorang } \\
\text { anak yang berumur } 10 \\
\text { tahun yang bernama } \\
\text { Aji Saka }\end{array}$ \\
\hline $\begin{array}{l}\text { Kaji Saka bersedia jadi } \\
\text { santapan Jawata Cengkar. }\end{array}$ & & $\begin{array}{l}\text { Aji Saka bersedia } \\
\text { menjadi santapan } \\
\text { Dewata Cengkar } \\
\text { asal kalau dapat } \\
\text { membunuh Dewata } \\
\text { Cengkar diberi tanah } \\
\text { seluas ikat kepala }\end{array}$ \\
\hline $\begin{array}{l}\text { Kaji Saka tidak bisa dimakan } \\
\text { karena kebal. }\end{array}$ & & $\begin{array}{l}\text { Aji Saka tidak bisa } \\
\text { dimakan karena } \\
\text { kebal. }\end{array}$ \\
\hline
\end{tabular}




\begin{tabular}{|c|c|}
\hline $\begin{array}{l}\text { Jawata Cengkar disuruh } \\
\text { mengulur destar Kaji Saka dulu } \\
\text { supaya bisa memangsanya. }\end{array}$ & $\begin{array}{l}\text { Aji Saka masuk ke } \\
\text { dalam kerongkongan } \\
\text { Dewata Cengkar }\end{array}$ \\
\hline $\begin{array}{l}\text { Destar tidak habis diulur } \\
\text { hingga Jawata Cengkar jatuh } \\
\text { ke laut dan mati kemudian } \\
\text { menjelma menjadi buaya putih } \\
\text { yang memusuhi Kaji Saka }\end{array}$ & $\begin{array}{l}\text { Tubuh Aji Saka } \\
\text { membesar sehingga } \\
\text { Dewata Cengkar } \\
\text { mati karena } \\
\text { kerongkongannya } \\
\text { pecah. }\end{array}$ \\
\hline $\begin{array}{l}\text { Kaji Saka menjadi raja } \\
\text { di Medang Kamulyan. } \\
\text { Mendirikan sekolah hingga } \\
\text { banyak raja lain yang belajar. }\end{array}$ & $\begin{array}{l}\text { Aji Saka mengulur } \\
\text { ikat kepala hingga } \\
\text { seluruh pulau Jawa } \\
\text { tertutupi. Aji Saka } \\
\text { menjadi raja. }\end{array}$ \\
\hline $\begin{array}{l}\text { Telur yang disimpan di } \\
\text { lumbung menentas menjadi } \\
\text { naga. Naga mencari ayahnya } \\
\text { hingga bertemu Kaji Saka. }\end{array}$ & $\begin{array}{l}\text { Aji Saka ingat akan } \\
\text { dua orang panakawan } \\
\text { yang ditinggal di Pulo } \\
\text { Majeti yaitu Dora dan } \\
\text { Sembada }\end{array}$ \\
\hline $\begin{array}{l}\text { Kaji Saka mau mengakui } \\
\text { anak asal sang naga bisa } \\
\text { mengalahkan buaya putih di } \\
\text { Segara Anakan. }\end{array}$ & $\begin{array}{l}\text { Aji Saka menyuruh Ki } \\
\text { Duduga dan Prayoga } \\
\text { mengundang Ki Dora } \\
\text { dan Sembada serta } \\
\text { membawa pusaka } \\
\text { yang dititipkan pada } \\
\text { mereka }\end{array}$ \\
\hline $\begin{array}{l}\text { Naga dapat mengalahkan } \\
\text { buaya putih dengan bantuan } \\
\text { Unajaya, pengawal Nyi Rara } \\
\text { Kidul }\end{array}$ & $\begin{array}{l}\text { Ki Dora mengajak } \\
\text { Sembada ke Medang } \\
\text { Kamulan tetapi ki } \\
\text { Sembada menolak. }\end{array}$ \\
\hline & $\begin{array}{l}\text { Aji Saka menyuruh Ki } \\
\text { Dora untuk memaksa } \\
\text { Ki Sembada agar } \\
\text { datang ke Medang } \\
\text { Kamulan. }\end{array}$ \\
\hline & $\begin{array}{l}\text { Ki Sembada tidak } \\
\text { mau pergi hinga } \\
\text { berkelahi dengan Ki } \\
\text { Dora dan keduanya } \\
\text { pun mati. }\end{array}$ \\
\hline & $\begin{array}{l}\text { Aji Saka menyuruh } \\
\text { Duduga dan Prayoga } \\
\text { menyusul ke Pulo Majeti }\end{array}$ \\
\hline & $\begin{array}{l}\text { Duduga dan Prayoga } \\
\text { melaporkan Dora dan } \\
\text { Sembada telah mati. } \\
\text { Aji Saka pergi ke Pulo } \\
\text { Majeti }\end{array}$ \\
\hline
\end{tabular}




\begin{tabular}{|l|l|l|}
\hline & & $\begin{array}{l}\text { Aji Saka menyesal } \\
\text { telah membuat } \\
\text { perintah yang } \\
\text { menyebabkan mereka } \\
\text { meninggal }\end{array}$ \\
\hline & & $\begin{array}{l}\text { sebagai peringatan } \\
\text { atas kesetiaan mereka } \\
\text { Aji Saka membuat } \\
\text { aksara Sunda yang } \\
\text { berbunyi hana } \\
\text { caraka (ada utusan) } \\
\text { data sawala (saling } \\
\text { berebut kebenaran) } \\
\text { pada jayanya (sama } \\
\text { kuatnya) maga batanga } \\
\text { (hingga menjadi } \\
\text { mayat). }\end{array}$ \\
\hline
\end{tabular}

\section{Resepsi}

Pada naskah Sajarah Galuh terlihat bahwa tokoh Aji Saka dianggap benarbenar ada dan merupakan penyebar aksara yang berasal dari dua puluh huruf pemberian Nabi Muhammad SAW. Ketika Aji Saka telah selesai berguru agama Islam kepada Nabi Muhammad SAW ia berganti nama menjadi Haji Saka lalu disuruh kembali ke Tanah Jawa dengan dibekali surat berisi 20 aksara yang diambil dari mega. Angka 20 mengingatkan kita kepada jumlah sifat wajib Allah SWT yang jumlahnya 20 atau disebut Sifat Dua Puluh. Selain itu, Nabi Muhammad juga menghadiahkan Doa Qunut kepada Aji Saka sebagai ganjaran atas "kenakalannya". Aji Saka telah dilegitimasi sebagai tokoh Islam dan merupakan sahabat Nabi Muhammad SAW. Hal ini menandakan bahwa CAS telah diterima sebagai bagian dari silsilah keturunan raja-raja dan bupati Galuh (Ciamis) yang telah menganut agama Islam.

Pendekatan Aji Saka sebagai shahabat Nabi Muhammad SAW merupakan salah satu bentuk legitimasi bahwa Aji Saka dan aksara Jawa yang dibawanya benar-benar Islami. Doa Qunut harus dibaca sir 'pelan' pada kalimat fa innaka taqdi menunjukkan bahwa pengarang Sajarah Galuh ingin memberikan legitimasi peranan Aji Saka sangat besar dalam penyebaran agama Islam di Jawa. Dengan melegitimasi Aji Saka sebagai tokoh penyebar Islam di Kabupaten Galuh (Ciamis) maka akan timbul perasaan bangga pada orang Galuh bahwa dirinya benar-benar penganut agama Islam yang paling dahulu (awwalul muslimin) sebagaimana pengakuan Nabi Ibrahim AS dalam Alquran.

(25) Lajeng baé namana ku Kangjeng Rasul, éta téh tuluy disalin, pun Haji Saka nu mashur, lajeng dipaparin isim, surat dua puluh yaktos.

(26) Tina méga waktuna aksara nyabut, sebab kersa Kangjeng Nabi, aksara nu dua puluh, keur di Nusa Jawa yakti, Jeng Nabi deui nyarios. 
(27) Ieu kula ieu nyieun Dunga Kunut, lebah fa innaka taqdhi, tangtuna ku euyna tangtu, éta dituluykeun tadi, engké dibacana tangtos.

(28) Meumeueusan ulah kakuping ku batur, sebab éta waktu tadi, nulis dituluykeun batur, ku sahabat geus kaharti, dawuhan Nabi nu yaktos.

Demikian pula, setelah Aji Saka mendapat perintah untuk menyebarkan aksara Jawa yang diberikan oleh Rasulullah, maka susunan aksara Jawa hana caraka data sawala pada jayanya maga batanga di dalam Sajarah Galuh dipakai untuk menyebut empat arah mata angin yang utama.

(01) Ungelna lebeting surat, ieu tulis aksara Jawa sayakti, Haji Saka kudu muruk, engké sadatang-datang, tangtu pisan Haji Saka jadi ratu, berekah ieu aksara, sinareng sapa'at Nabi.

(02) Lajeng dibaca ungelna, kieu pokna hana caraka yakti, sasaka wétan disebut, sareng data sawala, enya éta perenah sasaka kidul, sinareng pada jayanya, sasaka kulon sayakti.

(03) Jeung éta maga batanga, nya di kalér sasakana geus yakti, sang Haji Saka ngamaphum, éh ieu pandakawan, menta surat parebut ngajadi / gelut, sebab kieu aksarana, maga batanga téh mati.

Pada Mantri Jero terlihat bahwa pengarang telah menggunakan persepsi sejarah yang agak logis yaitu dengan memperkirakan keadaan pulau Jawa 1.500 tahun yang lalu. Jika pengarang menghitung jangka waktu tersebut dari tahun 1900an, kemungkinan bahwa Aji Saka hidup sekitar tahun 400 M. dengan demikian Aji Saka dianggap hidup sezaman dengan kerajaan Tarumanagara. Sebagaimana telah diketahui bahwa aksara Pallawa mulai dipergunakan untuk menulis prasasti pada masa kerajaan ini. Kepergian Aji Saka untuk berguru agama Buda ke negeri Atas Angin pun cukup logis karena hubungan kerajaan Tarumanagara dengan India dan China sangat baik. Dengan demikian, pengarang Mantri Jero berusaha menempatkan Aji Saka sebagai pelaku sejarah dan bukan hanya sekedar mitos. Penceritaan Aji Saka oleh Memed di dalam dialog antara Raden Wirautama dengan 
Yogaswara dimaksudkan untuk memberikan pendidikan moral bagi pemuda yang mau belajar menjadi pegawai pemerintah. Secara eksplisit Memed menanamkan pengajaran budi pekerti bagi para pemuda calon ambtenaar 'pegawai pemerintah' pada zamannya untuk selalu setia kepada atasan. Apapun perintah atasan harus selalu dipatuhi oleh bawahannya. Ia tidak boleh memercayai orang lain yang menjadi suruhan atasan apabila tidak ada saksi yang menguatkan perintah atasan tersebut. Jika perlu, lebih baik mati daripada harus menghianati perintah atasan.

Pada Sekar Aosan, pengarang berusaha menyajikan CAS sebagai bahan pengajaran moral dan pekerti. Tokoh Aji Saka sendiri terasa kurang menonjol jika dibandingkan dengan tokoh Ki Dora dan Ki Sembada. Bahkan pada Sekar Aosan cetakan kedua (1991) bagian pertama dihilangkan. Pengarang bermaksud menanamkan ajaran moral kapengkuhan 'kepatuhan' terhadap perintah atasan. Demikian pula sikap seorang pemimpin tidak boleh lanca-linci 'ingkar janji' sehingga menyebabkan bawahan binasa. Seorang pemimpin tidak boleh melupakan janji atau peraturan yang telah ia buat bersama orang lain atau bawahan sekalipun.

\section{PENUTUP}

Cerita Aji Saka (CAS) ternyata sangat digemari oleh masyarakat Sunda baik sebagai tokoh sejarah tradisional, maupun tokoh yang dimitoskan sebagai pencipta aksara Cacarakan. CAS tertulis di dalam naskah-naskah Sunda lama maupun di dalam buku-buku cetakan yang masih dipergunakan sebagai buku ajar di sekolah sampai akhir abad ke-20. CAS juga tertulis dengan berbagai variasi yang melahirkan versi-versi. Hal ini menunjukkan bahwa CAS berkembang sesuai dengan persepsi dan penerimaan masyarakat Sunda.

\section{DAFTAR SUMBER}

Baried, Siti Baroroh, dkk. 1994. Pengantar Teori Filologi. Yogyakarta: Badan Penelitian dan Publikasi Fakultas (BPPF) Seksi Filologi Fakultas Sastra Universitas Gadjah Mada.

Ekadjati, Edi S. 1986. Ceritera Dipati Ukur Karya Sastra Sejarah Sunda. Jakarta: Pustaka Jaya.

Ekadjati, Edi S. (Ed.). 1988. Naskah Sunda: Inventarisasi dan Pencatatan. Bandung: Toyota Foundation dan Universitas Padjadjaran.

Ekadjati, Edi S. dkk. (Penyunting). 1999. Direktori Edisi Naskah Nusantara. Jakarta: Masyarakat Pernaskahan Nusantara - Yayasan Obor Indonesia.

Ekadjati, Edi S. dan Undang Ahmad Darsa. 1999. Katalog Induk Naskah Nusantara Jilid 5a: Jawa Barat Koleksi Lima Lembaga. Jakarta: Masyarakat Pernaskahan Nusantara - Yayasan Obor Indonesia.

Ikram, Achadiati. 1980. Hikayat Sri Rama: Suntingan Naskah Disertai Telaah Amanat dan Struktur. Jakarta: UI Press.

Insani. 1957. Sekar Aosan. Bandung: Tarate 1991. Sekar Aosan. Bandung: Pamugat.

Pradotokusumo, Partini Sardjono. 1986. Kakawin Gajah Mada (Sebuah Karya Sastra Kakawin Abad ke-20 Suntingan Naskah serta Telaah Struktur, Tokoh dan Hubungan Antarteks). Bandung: Binacipta.

Robson, S.O. 1994. Prinsip-prinsip Filologi di Indonesia (Terjemahan oleh Kentjanawati Gunawan). Jakarta: RUL.

Sastraatmadja, R. Rg. 1951. Gandasari IV. Groningen-Djakarta:J.B. Wolters.

Sastrahadiprawira, R. Memed. 1983. Mantri Jero. Bandung: Rahmat Cijulang.

Sutrisno, Sulastin. 1981. Relevansi Studi Filologi. Yogyakarta: Liberty. 1983. Hikayat Hang Tuah: Analisa Struktur dan Fungsi. Yogyakarta: Gadjah Mada University Press.

Worsley, P.J. 1972. Babad Buleleng A Balinese Dynastic Genealogy. The Hague: Martinus Nijhoff-KITLV. 